\title{
PELATIHAN PEMBELAJARAN DENGAN STRTAEGI CRITICAL THINKING QUESTION
}

\author{
Imam Safi' $i^{1}$ dan Hery Muljono ${ }^{2}$ \\ Universitas Muhammadiyah Prof. DR. HAMKA Jakarta, Indonesia \\ 1imamsafii2077@uhamka.ac.id \\ 2herymuljono@uhamka.ac.id
}

\begin{abstract}
Abstrak
Pelatihan manajamen pembelajaran dengan critical thinking queston dimaksudkan untuk meningkatkan kemampuan para guru SD Muhammadiyah 3 Depok, Jawa Barat agar mampu malaksananakan praktik pembelajaran yang dapat membangun kemampuan berpikir kritis siswa. Metode yang dilakukan dalam pelatihan ini dibagi empat tahap, yaitu pengondisian, eksplorasi, elaborasi, dan konfirmasi. pemodelan tahap. Dalam kegiatan pelatihan ini para guru diberikan pemahaman secara teoretis tentang critical thinking queston, diberikan model pembelajaran yang menerapkan critical thinking queston, dan kemuadian secara bergantian mempraktikkan pembelajaran teknik critical thinking queston. Setelah megikuti pelatihan terdapat banyak perubahan positif dalam praktik pembelajaran yang dilakukan oleh para guru di SD Muhammadiyah 3 Depok, Jawa Barat. Pembelajaran tidak lagi berpusat kepada guru, melainkan berpusat kepada siswa yang lebih banyak memberikan kesempatan kepada siswa untuk mengajukan pertannyaan serta berpikir kritis ketika dihadapkan pada suatu fenomena. Pertanyaan-pertanyaan evaluasi yang dikembangkan guru pun lebih bervariasi, tidak hanya mengukur aspek kognitif tingkat rendah saja, tetapi juga mengukur berbagai ranah kognitif yang lebih tinggi lagi serta berbagai aspek kompetensi yang lebih komprehensif.
\end{abstract}

Kata kunci: Pelatihan, pembelajaran, critical thinking queston

\section{PENDAHULUAN}

Istilah berpikir kritis adalah salah satu dari beberapa konstruksi "fuzzy" dalam pendidikan yang sering digunakan oleh para peneliti dan praktisi, namun definisinya tidak jelas hingga dianggap sebagai bermasalah atau bahkan tidak perlu oleh beberapa peneliti (Atkinson, 1997; Kumaravadivelu, 2003; Vandermensbrugghe, 2004; Chen, 2017). Daniel Kahneman, yang memenangkan Hadiah Nobel 2002 untuk karyanya dalam pengambilan keputusan dan penilaian, memberikan bukti bahwa berpikir kritis oleh definisi apa pun bukanlah sesuatu 
yang terjadi, melainkan karena dilatih sehingga menjadi otomatis (2011).(Cargas, Williams, \& Rosenberg, 2017).

Berpikir kritis memiliki peran sentral dalam pembelajaran (Beyer, 1987; McPeck, 1981; Stupple et al., 2017). Mengajarkan pemikiran kritis merupakan komponen penting dalam program akademik apapun. Berpikir kritis melibatkan pemikiran yang disiplin, terarah dan terarah proses yang mencakup upaya untuk meningkatkan keputusan dan tindakan (Paul, 1993; Facione, 1990; Scheffer and Rubenfeld, 2000, Carter, Creedy, \& Sidebotham, 2017) Berpikir kritis melibatkan proses reflektif dalam membuat keputusan penilaian yang disengaja menggunakan proses kognitif dari analisis, interpretasi, evaluasi, penyimpulan, penjelasan, dan refleksi (Facione, 1990; Hendricson, et al., 2006; Carter, Creedy, \& Sidebotham, 2017b)

Pemikiran kritis adalah proses metakognitif yang, melalui penilaian reflektif yang bertujuan, meningkatkan peluang menghasilkan kesimpulan logis atas argumen atau solusi untuk masalah. Instruksi dalam berpikir kritis menjadi sangat penting karena memungkinkan individu untuk mendapatkan pemahaman yang lebih kompleks tentang informasi yang mereka hadapi dan mendorong pembuatan keputusan yang baik dan pemecahan masalah dalam aplikasi dunia nyata (Butler et al., 2012; Halpern, 2003; Ku, 2009; Dwyer, Hogan, \& Stewart, 2014). Berpikir Kritis memungkinkan siswa untuk membuat keputusan yang logis dan tidak bias, dan dalam situasi pendidikan telah terbukti mengarah ke hasil belajar yang lebih baik (mis., Facione, 2009; Halpern, 1998; Helsdingen, Van Gog, \& Van Merriënboer, 2011 (Heijltjes, van Gog, Leppink, \& Paas, 2014). Penilaian yang komprehensif terhadap pemikiran kritis (CT) merupakan tantangan, karena CT merupakan konstruksi multidimensional yang mencakup keterampilan dalam penalaran, pengambilan keputusan, dan pemecahan masalah (Willingham, 2007; (Bensley et al., 2016).

Selanjutnya, bagaiamana kemampuan para guru dalam melaksanakan praktik pembelajaran, di SD Muhammadiyah 3 Depok, Jawa Barat? Berdasarkan survey yang telah dilakukan, pembelajaran yang dilakukan oleh guru cenderung bersifat theacer center atau berpusat pada guru. Dengan demikian kurang 
menunjang kemampuan berpikir siswa secara kritis karena siswa cenderung pasif saat pembelajaran berlangsung.

Sejumlah hasil penelitian menunjukkan, bahwa pembelajaran dengan sistem theacer center kurang efektif jika dibandingkan dengan pembelajaran yang berpusat pada siswa atau student center. Temuan menunjukkan sebagai berikut: (1) Pemetaan pikiran yang berpusat pada guru mengungkapkan penurunan skor tes siswa, dan (2) pemetaan pikiran yang berpusat pada siswa menunjukkan peningkatan signifikan dalam nilai tes siswa. (Fun \& Maskat, 2010). Banyak dari penelitian lain yang berpendidikan tinggi yang sama-sama mengakui pentingnya pembelajaran yang berpusat pada siswa (Ramsden, 2003). Pendekatan ini memberi prioritas pada pendekatan berbasis siswa dan bukan penekanan yang kuat pada guru kontrol pengembang konten (Adams, 2002; Anderson, Johnson, \& Saha, 2002; Lea, Stephenson, \& Troy, 2003; Robertson, 2001),(Kim \& Davies, 2014)

Berdasarkan penelitian dari (Acat \& Dönmez, 2009) juga diperoleh sejumlah fakta yang menunjukkan efektivitas yang lebih tinggi pembelajaran yang berpusat kepada siswa daripada pembelajaran yang berpusat kepada guru. Berdasarkan penelitiannya, ia menyimpulkan, bahwa 1) menurut pendapat siswa berkat pendidikan yang berpusat pada siswa membuat efek yang lebih positif di lingkungan psikososial / sekolah-sekolah iklim sosial, 2) menurut pendapat siswa mereka dapat berinteraksi dengan mudah dengan dimensi kerja dan perangkat keras yang kurang fitur berkat aplikasi yang berpusat pada siswa. Metode ini mendukung siswa untuk menggunakan bahan, alat dan item teknologi, dan 3) Berkat pendidikan yang berpusat pada siswa, siswa lebih senang berada di kelas untuk mengikuti pembelajaran dan jarang keluar dari kelas.

Pembelajaran yang berpusat kepada siswa juga dapat digunakan untuk menciptakan kedekatan emosional antara guru dengan siswa sehingga dapat menunjang efektivitas pencapaian tujuan pembelajaran. Sebagaimana pendapat (Hamre \& Pianta, 2001; Ladd, Birch, \& Buhs, 1999; Roorda, Koomen, Spilt, \& Oort, 2011; Bosman, Roorda, van der Veen, \& Koomen, 2018), bahwa hubungan guru-murid yang afektif ditandai dengan tingkat kedekatan dan tingkat rendah 
yang tinggi konflik, berkontribusi pada penyesuaian sosial-emosional, perilaku, dan akademik siswa.

Selanjutnya, bertolak pentingnya pengembangan kemampuan berpikir kritis, efektivitas penerapan pembelajaran yang berpusat kepada siswa, serta beragam realitas yang kontraproduktif dari sistem pembelajaran yang diterapkan oleh para guru di SD Muhammadiyah 3 Depok, Jawa Barat di aatas, maka pengabdian kepada masyaarakat ini dilakukan, yaitu dengan mengambil tema "Pelatihan Pembelajaran Dengan Strtaegi Critical Thinking Question". Dengan demikian, melalui kegiatan pelatihan ini diharapkan mampu mengubah paradigm pembelajaran yang diterapkan para guru, yaitu dari sistem theacer center menjadi student center.

\section{MASALAH}

Berdasarkan pemaparan pada bagian pendahuluan di atas dapat diketahui, bahwa terdapat persolan yang dalam sistem pembelajaran yang diterapkan oleh para guru di SD Muhammadiyah 3 Depok, Jawa Barat, yaitu:

1) Pembelajaran yang diterapkan oleh para Guru di SD Muhammadiyah 3 Depok masih berpusat pada gur atau theacer center sehingga siswa cenderung bersifat pasif saat mengikuti poses pembelajaran.

2) Guru kurang melatih kemampuan berpikir siswa lebih tinggi karena pertanyaan-pertanyaan yang diberikan kepada siswa lebih banyak menggali kemampuan siswa berupa ingatan dan pengetahuan.

\section{METODE PELAKSANAAN}

Metode yang dilakukan dalam kegiatan pengabdian kepada masyarakat ini adalah berupa pelatihan, yaitu dengan mengacu pada prosesdur, 1) Tahap Persiapan, meliputi survey awal lokasi, kebutuhan mitra, serta urgensi atas kegiatan pelatihan yang akan dilakukan terhadap mitra, 2) Tahap Pelaksanaan Pelatihan, meliputi a) penjelasan tentang critical thinking question, b) tanya jawab tentang critical thinking question, dan 3) c. Simulasi, yaitu berupa pemberian kesempatan kepada mitra untuk mempraktikkan materi pelatihan yang diperoleh, dan d) 
evaluasi, yaitu berupa penilaian serta penguatan atas berbagai hal yang berkaitan dengan kegiatan simulasi dari perwakilan anggota mitra dalam mempraktikkan pembelajaran dengan menerapkan metode critical thinking question.

\section{PEMBAHASAN}

Kegiatan pelatihan ini terbagi atas tiga tahap, yaitu tahap pengondisian, tahap eksplorasi, tahap elaborasi, dan tahap konfirmasi.

\section{a. Kegiatan Awal}

Tahap awal dalam kegiatan pelatihan ini adalah pengondian yang dilakukan oleh satu narasumber. Hal ini penting untuk dilakukan agar seluruh peserta siap secara psikologis untuk mengikuti seluruh rangkaian kegiatan pelatihan. Dengan demikian, kegiatan pelatihan akan dapat berlangsung secara efektif.

Berikut ini adalah gambar dari salah satu narasumber yang sedang menyampaikan sambutan sekaligus pengondisian terhadap peserta pelatihan.

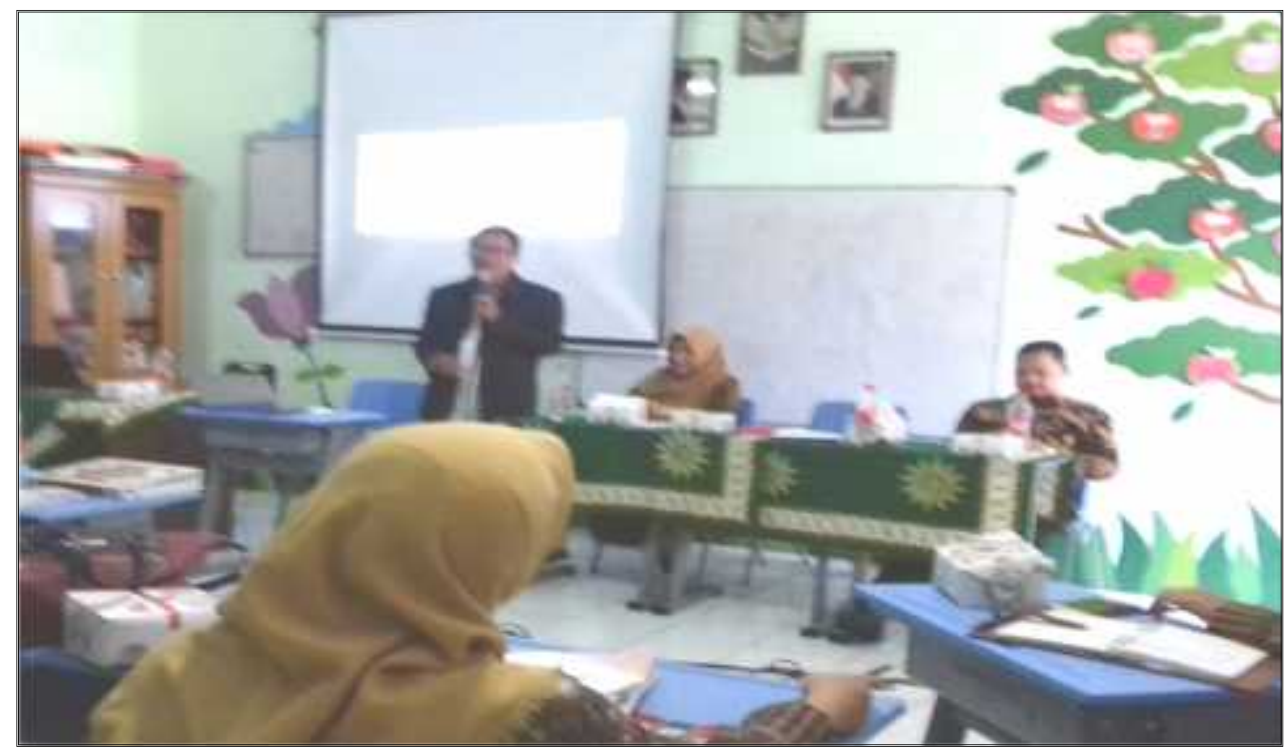

Gambar 1: Pengondisian peserta pelatihan pembelajaran dengan teknik critical thinking question

Dalam pengondisian tersebut narasumber menyampaikan tentang hasil survey awal mengenai kondisi pembelajaran yang berlangsung di SD Muhammadiyah 3 Depok, Jawa Barat. Di samping itu, ia juga menyampaikan 
tentang pentingnya perilaku inovatif, dan kritis, yaitu berupa upaya melangsungkan pembelajaran yang tidak lagi secara dominan berpusat kepada guru, melainkan berpusat kepada siswa. Hal ini penting untuk dikembangkan karena pembelajaran yang berpusat kepada siswa lebih mampu meningkatkan gairah belajar siswa sehingga mempu meningkatkan kemampaun berpikrir kritis para siswa. Hal ini sejalan dengan temuan (Fun \& Maskat, 2010), bahwa pembelajaran yang berpusat kepada siswa mampu meningkatkan hasil pembelajaran secara signifikan dalam nilai tes siswa. Sebaliknya, pembelajaran yang berpusat kepada guru menunjukkan penurunan skor tes siswa.

\section{b. Kegiatan Inti}

Setelah pengondisian, kegiatan pelatihan dilanjutkan pada tahap eksplorasi. Tahap eksplorasi dimaksudkan untuk menggali beragam informasi tentang pengetahuan yang dimiliki oleh peserta pelatihan mengenai critical thinking question. Hal ini penting untuk dilakukan karena dapat dijadikan sebagai landasan bagi narasumber serta fasilitator agar dapat menentukan teknik yang tepat dalam melangsungkan kegiatan pelatihan.

Berikut ini adalah gambar kegiatan ekplorasi dan elaborasi yang sedang dilakukan oleh salah satu fasilitator bersama dengan narasumber.

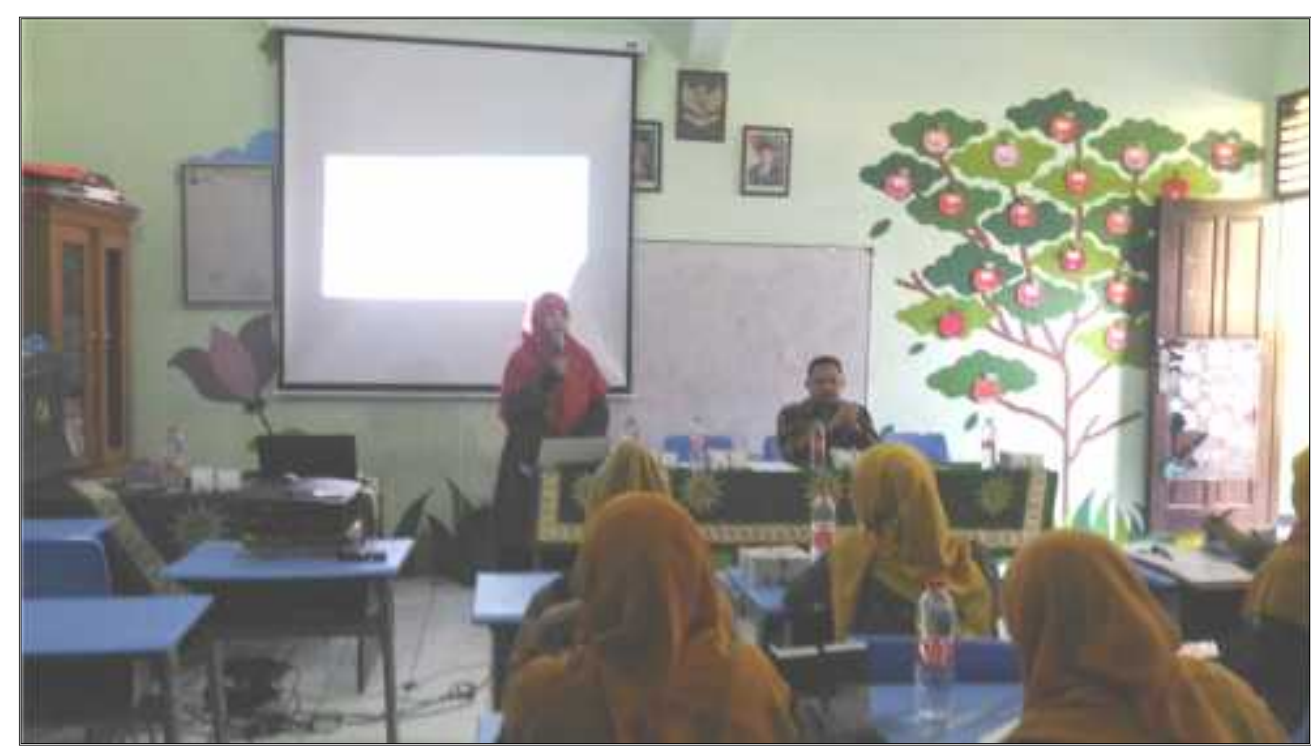

Gambar 1: Eksplorasi dan elaborasi pemahaman peserta pelatihan tentang pembelajaran dengan teknik critical thinking question 
Pada tahap eksplorasi tersebut, fasilator berusaha menggali pengetahuan dari seluruh peserta pelatihan dengan mengajukan berbagai pertanyaan kritis tentang beragam teknik pembelajaran, yaitu meliputi apa saja beragam teknik pembelajaran yang dapat diterapkan dalam kegiatan pembelajaran, apa yang dimaksud dengan critical thinking question, bagaimana kelebihan dan kekurangan dari teknik critical thinking question, bagaimana upaya untuk meningkatkan kemampuan berpikir kritis siswa, bagaimana upaya menerapkan pembelajaran dengan critical thinking question, dan lain sebagainya.

Berdasarkan hasil eksplorasi tersebut, dapat diketahui, bahwa pemahaman para peserta tentang critichal thinking question sebagai salah satu teknik pembelajaran memang belum optimal karena memang pembelajaran yang lebih banyak diterapkan oleh para guru adalah dengan teknik yang berpusat kepada guru. Berdasrkan hal tersebut, selanjutnya narasumber bersama dengan fasilatotor melanjutkan pelatihan ke tahap elaborasi. Pada tahap elaborasi narasumber bersama dengan fasilitator memberikan penjelasan lebih lanjut tentang efektivitas pembelajaran dengan menggunakan teknik critical thinking question serta dengan memberikan pemodelan tentang bagaimana upaya menerapkan pembelajaran pembelajaran dengan teknik critical thinking question. Efektivitas dari pemodelan ini mengacu pada pendapat dari (Potter, Bryce, \& Hartley, 2017), bahwa pembelajaran bebasis-model terbukti di seluruh pengembangan, perekrutan pembelajar88an berbasis model tampaknya meningkat seiring bertambahnya usia

Setelah pemodelan, selanjutnya peserta pelatihan diminnta untuk meranncang pemebelajaran yang berkaitan dengan topik tertentu. Untuk selanjutnya secara bergantian peserta melakukan simulasi pembelajaran dengan menerapkan teknik critical thinking question. Secara khusus, pembelajaran simulasi adalah istilah umum itu mengacu pada representasi buatan dari proses dunia nyata untuk mencapai pendidikan tujuan melalui pengalaman belajar (Abdulmohsen, 2010; Sukhai \& Mohler, 2017)

Berikut ini adalah gambar dari salah satu simulasi dari peserta pelatihan pembelajaran dengan teknik critical thinking question. 


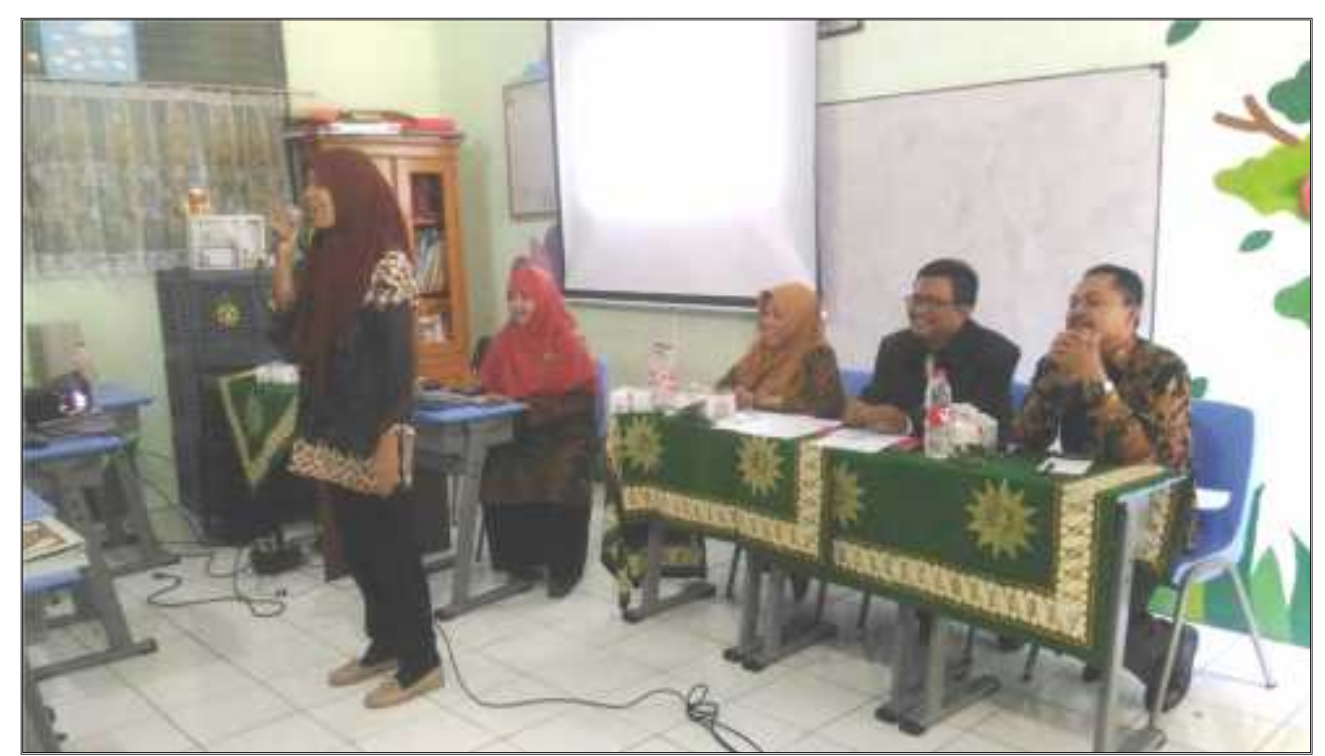

Gambar 1: Simulasi peserta pelatihan pembelajaran dengan teknik critical thinking question

Melalui kegiatan simulasi sebagaimana terlihat pada gambar di atas dapat diperoleh informasi tentang efektivitas dari kegiatan pelatihan yang sudah dilangsungkan. Umumnya peserta telah memahami serta dapat mempraktikkan pembelajaran dengan teknik critical thinking question. Pertanyaan-pertanyaan yang ditarakan oleh guru pada saat melangsungkan kegiatan pembelajaran tidak hanya sebatas menanyakan pengetahuan dan pemahaman siswa, melainkan sudah cukup beragam, yaitu berupa pertanyaan-pertanyaan yang bersifat analisis, sintesis, dan evalauatif.

\section{c. Kegiatan Akhir}

Setelah proses simulasi dari para peserta pelatihan, narasumber bersama dengan fasilatator memberikan evaluasi dan penguatan. Hal ini penting untuk dilakukan karena simulan dapat mengetahui kelebihan serta kekurangan tentang praktik pembelajaran yang telah dilakukan. Berikut ini adalah gambar dari salah satu narasumber yang sedang memberikan evaluasi atau penguatan atas praktik atau simulasi pembelajaran yang telah dilakukan oleh peserta pelatihan. 


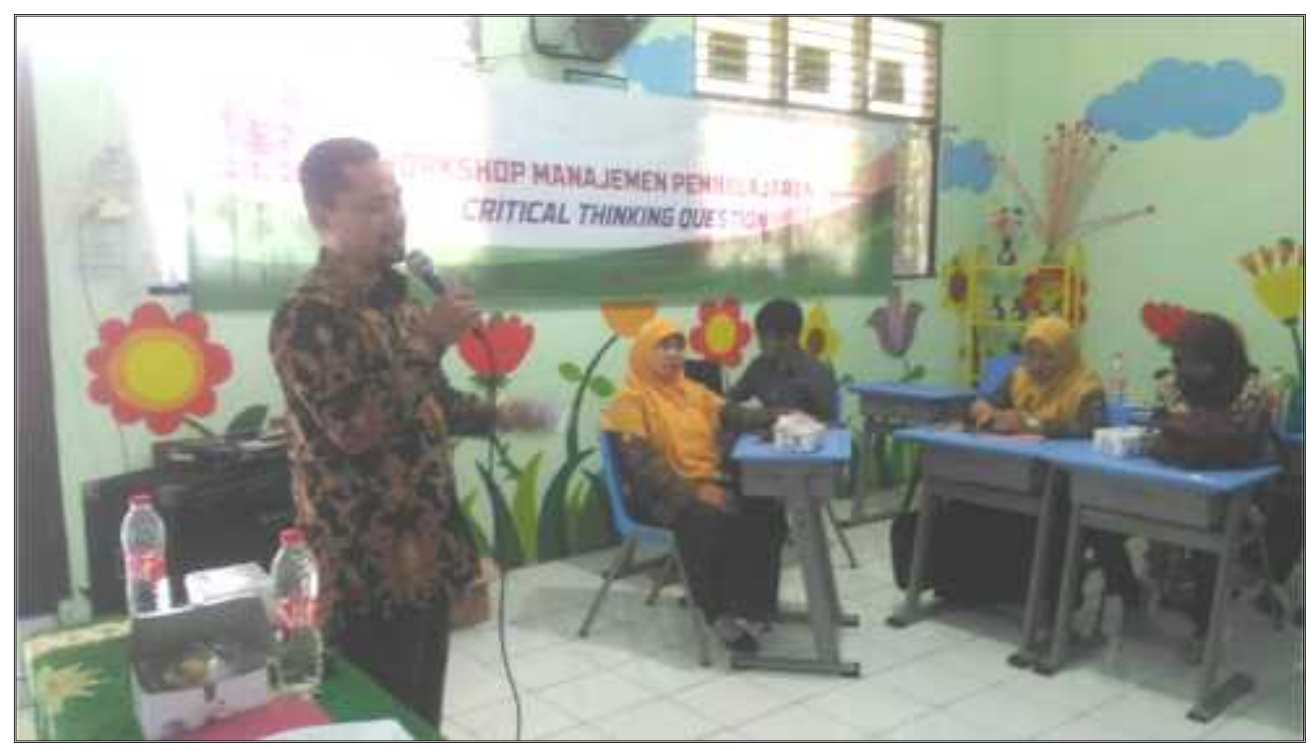

Gambar 1: Konfirmasi serta penguatan hasil pelatihan pembelajaran dengan teknik critical thinking question

Evaluasi dan penguatan yang diberikan kepada peserta pelatihan dimaksudkan untuk menyampaikan apreasiasi dengan tetap mengutarakan kelebihan serta kekurangan dari apa yang telah dipraktikkan. Dengan demikian para peserta akan mengetahui beberapa hal yang harus diperbaiki dalam proses pembelajaran. Dengan demikian, upaya untuk mendesain pembelajaran yang lebih inovatif, menyenangkan dan berpusat kepada siswa akan dapat terealisasi dengan baik. Hal ini sejalan dengan apa yang diutarakan oleh (Richardson 2005; Nielsen \& Kreiner, 2017), bahwa Umpan balik, dalam hal ini hasil evaluasi siswa dapat mengukur efektivitas pengajaran dan dapat bermanfaat dalam pengambilan keputusan. Penguatan juga dapat bermafaat untuk meningkatkan motivasi dan kepuasan belajar. ... ketika belajar dari umpan balik positif, mereka cenderung puas $\cdots($ Sojitra, Lerner, Petok, \& Gluck, 2018)

\section{SIMPULAN}

Pelatihan pembelajaran dengan teknik critichal thinking question merupakan salah satu teknik pembelajaran sebagai upaya untuk meningkatkan efektivitas pembelajaran. Melalui pelatihan pembelajaran dengan teknik critichal thinking question tersebut para guru dilatih agar mampu menerapkan pembelajaran yang 
tidak lagi secara monoton berpusat kepada siswa, melainkan berpusat kepada siswa. Pembelajaran yang berpusat kepada siswa memiliki peluang yang lebih leluasa dalam memberikan kesempatan kepada siswa untuk mengembangkan berpikir kritis sehingga kreativitas siswa dapat semakin meningkat.

Melalui pelatihan pembelajaran dengan teknik critichal thinking question para guru telah mendapatkan pemahaman yang komprehensif tentang upaya untuk melibatkan siswa secara aktif dalam kegiatan pembelajaran, yaitu dengan cara mengajukan beraragam pertanyaan yang dapat menggali tanggapan siswa secara kritis terhadap suatu fenomena yang dijadikan sebagai bahan pembelajaran. Dengan demikian, melalui teknik critichal thinking question pun akan dapat semakin dapat meningkatkan gairah belajar siswa.

\section{UCAPAN TERIMA KASIH}

Syukur alhamdulilah artikel kegiatan pengabdian kepada masyarakat ini telah dapat kami rampungkan. Hal ini juga menandai, bahwa kegiatan pengabdian kepada masyarakat yang telah kami usulkan telah berlangsung dan dapat berjalan dengan lancar. Hal ini tentu karena tidak lepas dari dukungan beberapa pihak, baik secara material maupun moral. Oleh karena itu, kami mengucapkan terima kasih yang sangat mendalam kepada UHAMKA dalam hal ini melalui Lembaga Penelitian dan Pengabdian Kepada Masyarakat yang telah mendanai demi keberlansungan kegiatan pengabdian kepada masyarakat ini. Di samping itu, rasa terima kasih yang sangat mendalam juga kami sampaikan kepada mitra pengabdian kepada masyarakat, dalam hal ini Ibu Kepala Sekolah beserta dewan guru SD Muhammadiyah 3 Depok, Jawa Barat yang telah berkenan meluangkan waktu untuk belajar bersama serta menjadi peserta dalam kegiatan pengabdian kepada masyarakat ini. Pun kepada seluruh anggota tim dan berbagai pihak, baik yang secara langsung maupun tidak langsung yang telah turut serta mendukung keberlangsungan kegiatan pengabdian kepada masyarakat ini, kami mengucapkan banyak terima kasih.

\section{DAFTAR PUSTAKA}

Acat, B., \& Dönmez, I. (2009). To compare student centred education and teacher centred education in primary science and technology lesson in terms of learning environments. Procedia - Social and Behavioral Sciences, 1(1), 1805-1809. https://doi.org/10.1016/j.sbspro.2009.01.320 
Bensley, D. A., Rainey, C., Murtagh, M. P., Flinn, J. A., Maschiocchi, C., Bernhardt, P. C., \& Kuehne, S. (2016). Closing the assessment loop on critical thinking: The challenges of multidimensional testing and low testtaking motivation. Thinking Skills and Creativity, 21, 158-168. https://doi.org/10.1016/j.tsc.2016.06.006

Bosman, R. J., Roorda, D. L., van der Veen, I., \& Koomen, H. M. Y. (2018). Teacher-student relationship quality from kindergarten to sixth grade and students' school adjustment: A person-centered approach. Journal of School Psychology, 68(December 2017), 177-194. https://doi.org/10.1016/j.jsp.2018.03.006

Cargas, S., Williams, S., \& Rosenberg, M. (2017). An approach to teaching critical thinking across disciplines using performance tasks with a common rubric. Thinking Skills and Creativity, 26, 24-37. https://doi.org/10.1016/j.tsc.2017.05.005

Carter, A. G., Creedy, D. K., \& Sidebotham, M. (2017a). Critical thinking evaluation in reflective writing: Development and testing of Carter Assessment of Critical Thinking in Midwifery (Reflection). Midwifery, 54(May), 73-80. https://doi.org/10.1016/j.midw.2017.08.003

Carter, A. G., Creedy, D. K., \& Sidebotham, M. (2017b). Critical thinking skills in midwifery practice: Development of a self-assessment tool for students. Midwifery, 50(April), 184-192. https://doi.org/10.1016/j.midw.2017.04.010

Chen, L. (2017). Understanding critical thinking in Chinese sociocultural contexts: A case study in a Chinese college. Thinking Skills and Creativity, 24, 140-151. https://doi.org/10.1016/j.tsc.2017.02.015

Dwyer, C. P., Hogan, M. J., \& Stewart, I. (2014). An integrated critical thinking framework for the 21st century. Thinking Skills and Creativity, 12, 43-52. https://doi.org/10.1016/j.tsc.2013.12.004

Fun, C. S., \& Maskat, N. (2010). Teacher-Centered Mind Mapping vs StudentCentered Mind Mapping in the teaching of accounting at Pre-U level- An action research. Procedia - Social and Behavioral Sciences, 7(C), 240-246. https://doi.org/10.1016/j.sbspro.2010.10.034

Heijltjes, A., van Gog, T., Leppink, J., \& Paas, F. (2014). Improving critical thinking: Effects of dispositions and instructions oneconomics students' reasoning skills. Learning and Instruction, 29, 31-42. https://doi.org/10.1016/j.learninstruc.2013.07.003 
Kim, A. K., \& Davies, J. (2014). A teacher's perspective on student centred learning: Towards the development of best practice in an undergraduate tourism course. Journal of Hospitality, Leisure, Sport and Tourism Education, 14(1), 6-14. https://doi.org/10.1016/j.jhlste.2013.12.001

Nielsen, T., \& Kreiner, S. (2017). Course evaluation for the purpose of development: What can learning styles contribute? Studies in Educational Evaluation, 54, 58-70. https://doi.org/10.1016/j.stueduc.2016.10.004

Potter, T. C. S., Bryce, N. V., \& Hartley, C. A. (2017). Cognitive components underpinning the development of model-based learning. Developmental Cognitive Neuroscience, 25, 272-280. https://doi.org/10.1016/j.den.2016.10.005

Sojitra, R. B., Lerner, I., Petok, J. R., \& Gluck, M. A. (2018). Age affects reinforcement learning through dopamine-based learning imbalance and high decision noise-not through Parkinsonian mechanisms. Neurobiology of Aging, 68, 102-113. https://doi.org/10.1016/j.neurobiolaging.2018.04.006

Stupple, E. J. N., Maratos, F. A., Elander, J., Hunt, T. E., Cheung, K. Y. F., \& Aubeeluck, A. V. (2017). Development of the Critical Thinking Toolkit (CriTT): A measure of student attitudes and beliefs about critical thinking. Thinking Skills and Creativity, 23, 91-100. https://doi.org/10.1016/j.tsc.2016.11.007

Sukhai, M. A., \& Mohler, C. E. (2017). Simulation learning. Creating a Culture of Accessibility in the Sciences, 249-255. https://doi.org/10.1016/B978-0-12804037-9.00022-X 